\title{
Diagnosis of Challenges and Scrutinization of Opportunities in Regard to Harnessing of Hydropower Potential in Nepal
}

\author{
Tejaswi Sharma \\ Kathmandu, Nepal
}

\begin{abstract}
Nepal is a naturally blessed hydro-resources rich country with one of the highest per capita hydropower potentials in the world, yet hungry of economic enhancement through hydropower development. This paper emphasizes on challenges in this sector, mainly technical and investment (financial) challenges, among many, for not being fully able to harness this sector. Among the technical challenges, fragile geology, hydrologic variability, high rate of sedimentation, difficult terrain with dispersed settlement, stringent environmental concerns, lack of policy interventions in hydropower development etc have been the major obstacles to overcome. Similarly, regarding financial challenges, constraints in mobilizing funding from Financial Intermediaries (FIS), foreign exchange risk, repatriation risk, sovereign risk (country risk), payment risk, construction risks (time and cost overrun), hydrological risks, local level disputes and risks need to be conveniently addressed to.
\end{abstract}

This paper tries to diagnose the huge opportunities that hydro sector has in Nepal. Despite many of these challenges, a lot of opportunities do exist to harness the enormous hydro potential. As of this, Nepal is blissed with bountiful hydro resources, there are possibility of mega dams with huge storage capacity, there have been possibility of multipurpose diversion schemes, export of surplus energy, cross border grid and integration of South Asian Pool, upstream benefits and advantages (high heads, less sediment yield, cascade projects etc), replacement of fossil fuels, huge demand of electrical energy from hydropower, enhancement of economic prosperity thereby attainment of Sustainable Development Goals (SDGs) which are some of the pertinent opportunities that could be grasped upon by Nepal.

Nepal's economic prosperity is highly reliable on the puritanical and judicial development of her hydro assets. But still a lot needs to be undertaken for luring bigger investment to hydro sector. Analyzing all the issues, challenges and opportunities underlined, the unanimous efforts of all the stakeholders is a must for the developer to government institutions, and policy makers, to investors and donors, to consumers and project affected population.

Keywords:- Hydropower, Challenges, Opportunities, Nepal, Hydro Resources, Energy.

\section{INTRODUCTION}

Hydropower, a renewable source of energy generated from flowing water, is a sustainable source with almost zero input cost contributing non-polluting benefits releasing no heat or noxious gases and having low operating and maintenance cost offering flexible and reliable operations. The hydropower development would be the fundamental key to Nepal's development in prosperous economic growth, gaining deep inroads into the national goal and major strive in alleviation of poverty (Adhikari, D., 2006).

Despite having one of the highest per capita hydropower potentials in the world, Nepal, is still a way far behind in tapping the rich hydro resources. The Nepalese perspective in viewing the hydropower has been to-

a) Rural and urban economic enhancement through clean energy

b) Export of surplus energy and revenue generation from it

However, due to many ups and downs, the materialization of all these goals have been insufficient mainly due to jejune planning and investment in generation, transmission and distribution. However, due to lacking legal and regulatory framework, many hydro development projects are delayed. Collaborative policy and investment efforts must address the disparity, differences and despair between the available plentiful renewable energy resources and the chronic shortage of commercial energy services, with intensive focus on consumer satisfaction with energy services in the near term, rationalization of tariffs in the medium term and sector reforms in the long term ((RPP NEP44219), 2013)).

The overall aggregate energy pattern in the Fiscal Year 2016/17 could be manifested as: (Nepal Electricity Authority, 2017)

> Nepal Electricity Authority's total hydropower plants (including small power stations) generated at an average a total of $2305.17 \mathrm{GWh}$ energy.

$>$ The total energy imported from India reached about 2175.04 GWh with average power import for the Fiscal Year 2016/17 being 250MW via transmission lines including Dhalkebar-Muzaffarpur transmission line.

$>$ The total energy purchased from Independent Power Producers (IPPs) within Nepal was about 1777.24 GWh.

$>$ The total number of electricity consumers reached to 3.26 million including community and bulk buyers during the Fiscal Year 2016.17. 


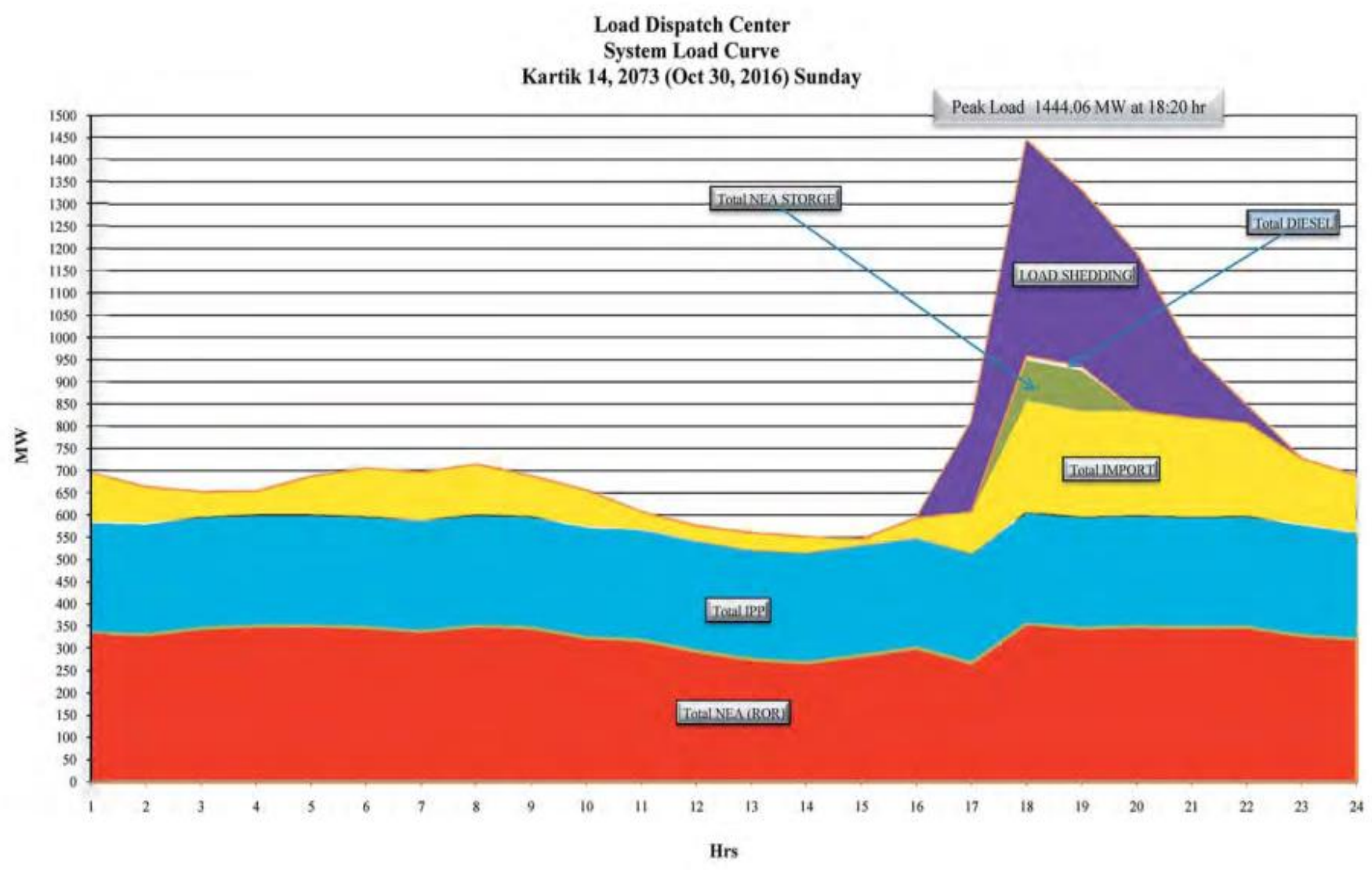

Fig 1:- System Load Curve (Nepal Electricity Authority, 2017)

The above figure depicts the system load curve assessed on October 30, 2016 which clearly depicts that there is still a huge gap between the peak demand and the total installed capacity, the enunciation of which is that there exists an enormous opportunity for hydropower development in Nepal despite some of the rudimentary challenges to be faced.

As per the $14^{\text {th }}$ National Plan of National Planning Commission, the total installed capacity is $829 \mathrm{MW}$ and the total length of transmission lines has reached to 2848 kilometers. It was aimed to make access of electricity to $87 \%$ of the population till the end of $13^{\text {th }}$ National Plan but only $74 \%$ had been rendered the accessibility.

\section{OBECTIVES:}

The main objectives of the author in presenting this paper is portrayed as below:

$>$ To diagnose the challenges that has hindered the development of hydropower in Nepal

> To scrutinize the wide range of opportunities left open to harness the enormous hydro-potential in Nepal.

To assess the technical and financial hindrances so as to foster the economic prosperity of Nepal through hydro development

To enunciate on the attainment of Sustainable Development Goals (SDGs) by exploiting Nepal's immense hydro-resources
To analyze the issues and challenges followed by lining up of opportunities to escalate the investment in hydro sector in Nepal

\section{DIAGNOSIS OF CHALLENGES}

Through the development of hydropower, a lot of befitting perspicacity in regard to national economic enhancement could be attained but through there a lot of technical and financial challenges which the hydropower developers could pass through which has been vividly enunciated as below:

\section{* Technical Challenges:-}

Nepal is a naturally fanciful hydro resources rich country yet starving for economic prosperity through hydropower development. But being so due to fragile geology, hydrologic variability, geotechnical constraints, difficult terrain, and sparse hydro meteorological network etc., plentiful of technical challenges had to be borne up with for hydropower development. Some of the technical challenges for hydropower development in Nepal could be limpidly summed up as below (Baral, S., 2014, Fundamentals of Hydropower Engineering)

\section{A. Fragile Geology}

Nepal can be divided into eight district physiographic units: the Terai, the Siwialik (Churia) Range, the Dun valleys, The Mahabharat range, the Midlands, the Fore Himalays, the Higher Himalays and the inner and Trans Himalayan Valleys, each having district altitude, 
topographical, climatic and vegetation characteristics. Moreover, geologically Nepal can be divided into five major tectonic zones: the Terai, the Siwaliks, the lesser Himalaya, the higher Himalaya and the Tibetan-Tethys Himalaya, separated by major thrusts and faults; two of these Main Central Thrust (MCT) and Main Frontal Thrust (MFT) being fundamentally distinct tectonic zones against each other and each of these zones are characterized by their rock types, age, metamorphism, structures and geological history.

The Himalaya are the most active and fragile mountain range in world, often characterized by a live mountain with active tectonics. Since, the northward moving Indian plate pushes against the more stable Tibetan block, the Himalaya is still rising and its rocks are under constant pressure. This pressure forces the Himalaya to rise and move horizontally southward along major thrusts which is often manifested in frequent earthquakes. In addition, the inherently weak geological characteristics of the rocks make the Himalaya fundamentally fragile. Hence, taking into consideration all these risks including the terrain's geological nature and interplay of various triggering factors, the development of hydropower projects should be carried out. (Uprety, B.N., 2000).

\section{B. Hydrologic Variability}

Nestled in the Hindu Kosh Himalayas, Nepal is characterized by warming trend over the past few decades and expected to have averaged mean temperature increase of $1.2^{\circ} \mathrm{C}$ and $3^{\circ} \mathrm{C}$ by 2050 and 2100 . It is because of glacier retreat and ice melt that more than two thousand glacial lakes size and volume is increasing, making them more susceptible to Glacial Lake Outburst Flooding (GLOF). Continued glacier retreat can considerably reduce dry season flows fed by glacier melts in the monsoon might intensity under climate change thereby enunciating to enhance variability of river flows. Greater unreliability of dry season flow posing potentially serious risks to discharge in the lean season, GOLF, increased runoff variability leading to risk of flooding and note intense precipitation events (particularity during the monsoon) remains as important factor of uncertainty regarding hydrologic variability for hydropower developers to invest in Nepal. (Agrawal, S., Reyoholds et.al., 2003).

The best way to mitigate this challenge is by developing hydropower with due analysis of long term hydrological data (particularly 500 or 1000 years return period) or choosing the one with best hydrological potential.

\section{High Rate of Sedimentation}

The high rate of sedimentation is affecting the hydropower plants which principally decreases the capacity (life) of reservoir (by decreasing the dead storage capacity) and fundamentally causing erosion thereby reducing the efficiency and life of turbine components. Himalayan rivers have too much sediments mainly due to presence of weak rocks and extreme relief representing hard abrasive mineral/rock fragments with the shape, size and mineral content of sediment depending on distance traversed by particles, gradient of the river and the geological formation of the river course and catchment area (Bhola Thapa et.al. 2004, Ph.D. Thesis Sediment in Nepalese Hydropower Projects). Sedimentation in 1993 Monsoon (MarchDecember 1993) in the Kulekhani reservoir was 519.36 ha$\mathrm{m}$ thereby decreasing the reservoir capacity by 5.19 million cu.m.( Keshar Man Sthapit, 1996).

The best way to mitigate this risk is through sediment monitoring and implementing necessary counter measures to protect the reservoir from sedimentation like watershed management, construction of sediment traps, structures and management of the sediment within the reservoir and watershed.

\section{Geopolitical Situation and Topographical Constraint (difficult terrain with dispersed settlement)}

Nepal is landlocked by India on three sides (south, east and west) and China's Tibet Autonomous Region to the north. West Bengal's narrow Siliguri corridor or chicken's neck separate Nepal and Bangladesh. Nepal measures about $800 \mathrm{kms}$ (497 miles) along its Himalayan axis by 150 to 250 kilometers (93 to 155 miles) across with coordinates at $26^{\circ}$ and $31^{\circ} \mathrm{N}$ and $80^{\circ}$ and $81^{\circ} \mathrm{E}$ having an area of $1,47,181$ square kilometers $(56,827$ sq. miles) (www.wikipedia.org, Assessed: 16 October, 2017) . Due to challenging terrain with disseminated settlements, long transmission lines are required and the costs of connection to national or regional grids could be two to five times as high as those of electricity generation in large, centralized plants (Rechsteiner, 2001). The only way to attenuate this risk is by amending the policy level strategy thereby promoting micro hydropower (with low cost) in such difficult terrain with displaced settlement.

\section{E. Stringent Environmental Concerns}

The stringent environmental considerations like legal requirement and environmental screening, areas requiring monitoring and auditing has by large become a hindrance to the hydropower development in Nepal.

The table below manifests the priority ranking of climate change impacts for Nepal (Agrawal, et.al. 2003)

\begin{tabular}{|c|c|c|c|c|}
\hline Resource/Ranking & $\begin{array}{c}\text { Certainty of } \\
\text { Impact }\end{array}$ & $\begin{array}{c}\text { Timing of Impact } \\
\text { (Urgency) }\end{array}$ & Serenity of Impact & $\begin{array}{c}\text { Importance of } \\
\text { Resource }\end{array}$ \\
\hline Water resources and hydropower & High & High & High & High \\
\hline Agriculture & Medium-low & Medium-low & Medium & High \\
\hline Human health & Low & Medium & Uncertain & High \\
\hline Ecosystems/Bio-diversity & Low & Uncertain & Uncertain & Medium-high \\
\hline
\end{tabular}

Table 1:- Priority Ranking of Climate Change Impacts of Nepal (Source: Agrawal et.al. 2003) 
The only way to mitigate this is through designation of a margin with a bit of leniency regarding environmental impact for least development countries like Nepal by the United Nations (UN) via strong lobbying by the government.

\section{F. Lack of Policy Interventions Regarding Hydropower Development}

The first comprehensive regulations on hydropower in Nepal were issued in the early 1990s, fundamentally to bridge the gap between demand and supply and reduce forest degradation. Other aims included funds raising for infrastructure development from the non-public sector and mobilizing internal resources for hydropower development. The slower pace of hydropower development by public sector is a clear blow to the expectation of planners who believed that an appealing hydropower policy would fascinate new investment capital to Nepal. The following three-pronged approach would aid in the prolonged continuity of hydropower development in Nepal (Shaligram Pokharel, 2001.)

\section{A Decentralized approach for small-scale projects:}

Small rivers with catchment area less than $300 \mathrm{~km}^{2}$ would be suitable for generating micro hydropower, which could replace kerosene used for lighting diesel used for processing agricultural products.

\section{A Centralized approach for medium scale projects.}

Medium sized rivers with catchment areas between 300 and $1000 \mathrm{~km}^{2}$, suitable for both runoff the river and storage projects, should be linked to the national grid which could balance the energy demand and supply.

\section{An export oriented approach for large-scale projects}

Rivers with more than $1000 \mathrm{~km}^{2}$ catchment area are suitable for large scale storage and multipurpose projects should be focused on export of electricity since it could be a shared benefit.

\section{G. Other Challenges}

Undeveloped proper infrastructures like access roads and transmission networks is another obstacle to developing hydropower in Nepal. The institutional setup is also quite not strengthened in regard to the appropriate policy level decisions which should be furnished corresponding to effective hydropower development in Nepal. The isolated load centers not connected to national (regional) grid center was also distracted the hydropower developers as it causes an additional cost to develop transmission line network.

The figure below portrays the problem tree along with effects, core problem and causes of energy sector in Nepal.

\section{Problem Tree for the Energy Sector}

EFFECTS

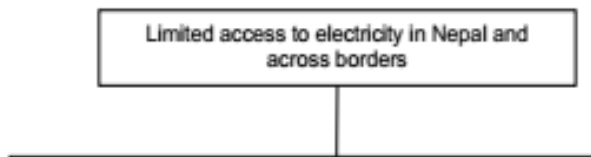

CORE PROBLEM
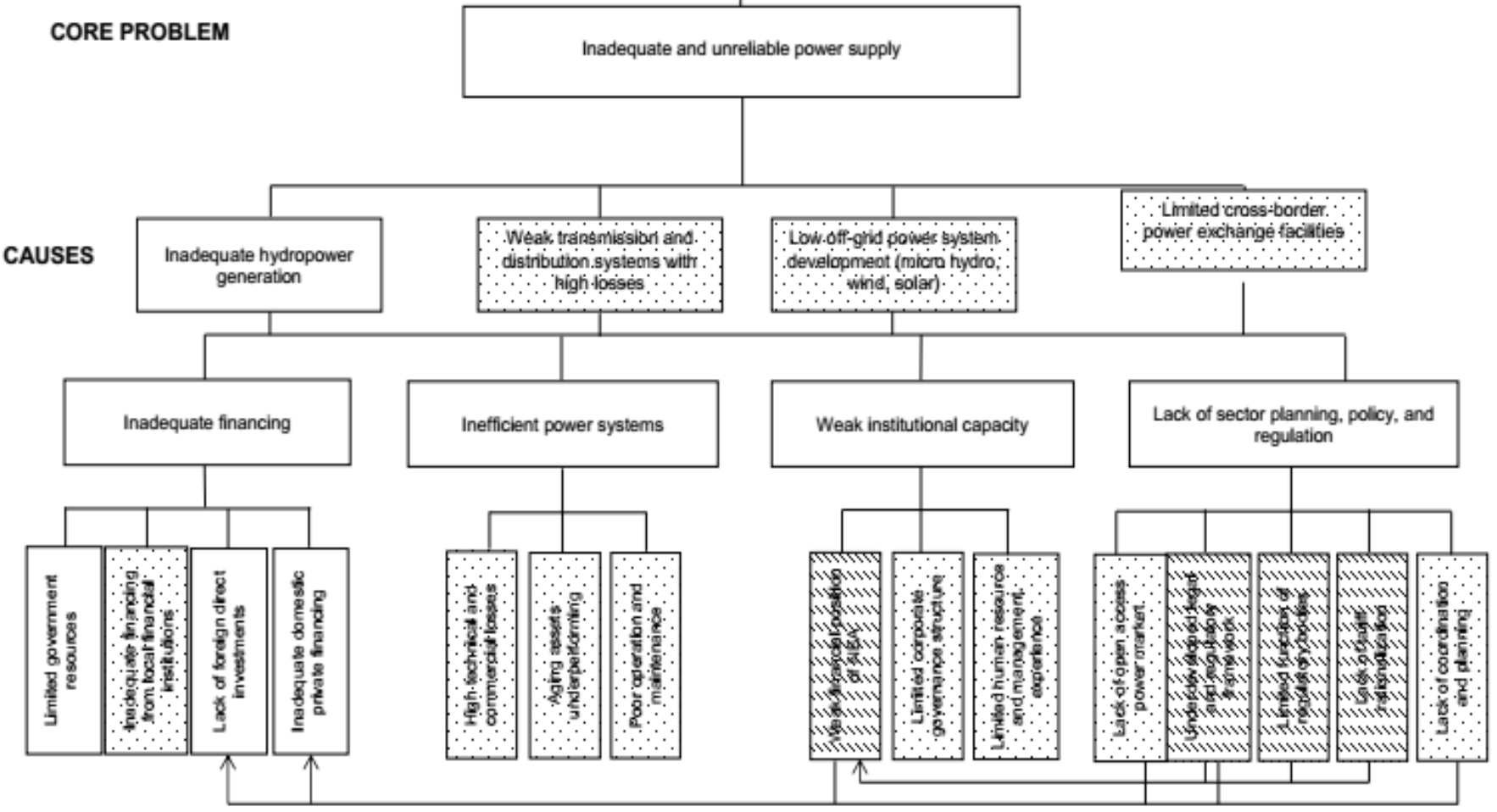

Fig 2:- Problem Tree for the Energy Sector (Source: RRP NEP 44219, 2015) 
Regardless of all these challenges, the hydropower development is one of the best ways to blow up the economic property of Nepal one hand from government's perspective and to get enormous benefit by selling the energy from the developer's perspective.

\section{* Investment (Financial) Challenges:-}

As per the report of National Planning Commission, $14^{\text {th }}$ year plan, $74 \% \%$ of the population in Nepal had access to electricity in contrast to aim of reaching to $87 \%$ which clearly depicts that more than $25 \%$ of the population are still deprived of electricity, which is a bad indicator of economic prosperity but though a solid market for hydropower investor in Nepal. Moreover, if the export of surplus energy to Indian market is added, then the increment in market size would be by more than a magnitude or more. This fabulous market for electricity exhibits the investment opportunity and attracts for limitless investment in hydropower.

The investment in this sector is heavily reliant on on the cautious management of various types of risks and hence mitigating such risks including an operative insurance program is an important step in effective and efficient risk alleviation. Some of the fundamental financial challenges in hydropower sector can be summed up as (Ratna Sansar Shrestha, 2007).

\section{A. Major Constraints in Mobilizing Funding from Financial Intermediaries (FIS)}

In this regard, equity investment is the major ramification in hydropower by investors with complementary debt financing (debt equity ratio is generally considered 70:30) from financial intermediaries. In addition to this, an entrepreneur's ability to mobilize debt funding is equally important. Some of the major constraints in mobilizing funding from FIS could be summarized as below - (Shrestha, Ratna Sansar, 2007).

\section{Market failure and portfolio mismatch in financial intermediaries (FIS)}

Because of short term nature deposit base (the debts offered by the banks and their capital base are limited) market failure seems to be pronounced and it will be a portfolio mismatch for them to offer long term loans. Hence, FIS seem hesitated to assist private developers in participating in hydropower development in the needful way.

\section{Lack of project finance instrument}

Project financing, also called non-resource financing, is such that the very project is accepted by FIS as collateral and no extra (external) collateral is required thereby the debt financing institutions will be encircled with limited resource. In this case, the proponent doesn't need to lodge other tangible or intangible assets as collateral which doesn't seem pragmatic in Nepal in the present economic context. Hence, in order to encourage hydropower developers, funding should be made available by FIS on project finance basis.

\section{Lack of 'due diligence' capability in FIS:}

Hydropower sector comprises of a number of disciplines like civil, electrical, mechanical engineering along with hydrology, geology, hydro morphology as well. In order to invest in hydropower, one needs to have expertise of all these disciplines in a house which FIs in Nepal lack and hence they don't show interest in investing in hydropower because of not having required'due diligence' capability.

\section{Central Bank Guidelines Insensitive to Power Sector}

Loans are classified by the Central Bank of Nepal, Nepal Rastra Bank (NRB) as follows:

\section{- Pass and watch list Loans}

Loans which have not been serviced for three months are pass loans. Watch list loans also includes the same pass loans but encompasses those who's principal and interest have not been paid within the repayment period sub standards.

\section{- Sub-standard loans}

Non-performing Loans (NPL) not serviced for three to six months are sub-standard loans.

\section{- Doubtful Loans}

Loans not serviced for six months to one year are doubtful loan.

\section{- Loss Loans}

Loans whose interest and/or installment of principal has not been paid for more than one year are loss loans.

The provisioning requirements for pass loan is $1 \%$, watch list loan is $5 \%$, substandard loan is $25 \%$, doubtful loan is $50 \%$ and loss loan is $100 \%$.

In the power sector, time overrun is a major challenge everywhere. For e.g. Chameliya HEP (30 MW), Kulekhani III (14 MW), Upper Trishuli 3A (60 MW), Upper Tamakoshi (560 MW), are still not commissioned for energy production after such a long years of gap too.

If $100 \%$ provisioning by banks is commenced in hydropower sector, the investor's risk to becoming insolvent would be more which would on one hand, unsympathetically sway the power sector and on the other hand, adversely affect the economy of the country as well.

\section{B. Foreign Exchange Risk}

The two options available for developer is either to borrow locally or from foreign institutions in regard to same security. Because of relatively stronger foreign currency compared to Nepalese currency foreign exchange risk can be mitigated by

$>$ Denomination of loan in local currency

$>$ Denomination of rate of revenue in foreign currency

$>$ Provision of insurance coverage against cost escalation for an increase in import cost. 


\section{Repatriation Risk}

This risk typically concerns the lender who is not able to repatriate the proceeds of debt servicing and a foreign equity investor is also subject to this risk trend of enacting. Developing countries have legislation guaranteeing repatriation so that the lender would be able to make a loan and won't be subjected to exorbitant rate of interest. In Nepal, legal provisions guaranteeing repatriation for hydro projects are Foreign Investment and Technology Transfer Act, 1992 and Electricity Act, 1992.

\section{Sovereign Risk (Country Risk)}

A foreign investor would get exposed to risks such as government's credit worthiness, possibility of confiscation, expropriation and nationalization (CEN), changes in local political environment and enforceability of contracts which are sovereign (country) risks. The multilateral Investment Guarantee Association (MIGA), a member of the World Bank Group, ensures against such risks for a fee but however the insurance provision is limited only to foreign investors.

\section{E. Payment risk}

Due to lack of credit worthiness (no credit histories, poor management, and high technical leaders) from the state owned utilities, in many developing countries, developers ask for issuing a counter guarantee to cover the payment risk. Counter guarantee basically obliges government that the utility (energy buyer) pays its dues to the developers in time and failing to do so, the government promptly makes payment to mitigate the delinquency of the utility. The best way to mitigate this risk is to have a letter of credit put in place by the utility with the Independent Power Producers (IPP).

\section{F. Construction risks (time and cost overturn)}

These risks result in loss of revenue, raising cost due to inflation, and increase in interest amount of the debt financing and can even attract penalty for late delivery of energy. One of the ways to mitigate this risk is through insurance coverage (risks like Contractors' all risks (CAR), Time at Risk (TaR), Erection all Risks (EAR), professional liability etc.) and also imposition of liquidated damage for delayed substantial completion of the project.

\section{G. Hydrological risks}

The 'take or pay' nature of PPA incorporates the guarantee of all energy produced by a plant, depending on the discharge of water, irrespective of dry or wet season, to be turned into cash. However, if the water level is very low due to change in hydrology of the catchment area, climate variation or precipitation variability, then those projects are the developers own risk. Seasonal rainfall pattern might affect the water availability emanating the fact that the generation may fall below contract level, thus threatening the revenue stream of the projects. According to OECD/World Bank Creditor Reporting System (CRS) database, it has been manifested that roughly $50-65 \%$ (in terms of investment dollars) and 26-33\% (in terms of number of projects) of donor portfolios in Nepal are potentially affected by climate risks. The most effective way of mitigation of this risk is by designing the project accordingly by gathering the hydrological data for reasonable number of years (100 or 500 years return period) or selecting the project with better hydrological potential.

\section{H. Local level disputes and risks}

The cooperation and collaboration of differently positioned stakeholders including the local community is very essential and indispensable. It is obvious that the local public demand the share of the benefits to be accrued from the project development. Water conflicts might arise with upstream hydropower use and downstream irrigation use. The demand of local people might create a conflict over right to natural capital which leads to increase in cost of hydropower production due to time overrun. The recent example of it is Upper Tamakoshi (456 MW) project, the largest hydropower project under construction, where due to the issue of demand of increased share by local people hindered the project for some months. Several other projects namely Khimti (60 MW), Bhotekoshi (450 MW), Buddhi Gandaki (1200 MW), Upper Bafeli (50 MW) have been facing problems associated with benefit sharing.

The only to mitigate this risk is by involving local people in benefit sharing. The best example of it is Chilime (22 MW) hydropower project which was constructed with domestic investment and manpower and 10 percent share was given to the people of affected VDC and residents of Rasuwa district. Involvement of local people in benefit sharing with allocated shares helped develop other subsidiary projects of Chilime namely Sanjen (42.5 MW), Upper Sanjen (14.8 MW) and Rasuwagadhi (111 MW) smoothly as local people have taken ownership of the projects. From this, it could be manifested that local level obstacles could be attenuated if some portion of project ownership is transferred to local residents in a way that they would be getting benefits from their resources.

\section{SCRUTINIZATION OF OPPORTUNITIES}

Nepal had a lot of challenges (technical and financial) to bear up, persevere and withstand for exploiting her immense hydro resources as characterized above. But it is better late than never that it is absolutely rudimentary and crucial to gradually extenuate and mitigate these challenges as there are pellucid wide ranges of opportunities left open to harness the enormous hydro potential which could be delineated and interpreted as below:

\section{A. Blissed with bountiful hydro resources:}

Nepal has an enormous potential to tap the hydropower which could be the best source of domestic energy supplies and a source of export revenues as well. In Nepal, it is estimated that more than $80,000 \mathrm{MW}$ of gross potential and 40,000 MW of economically feasible hydropower potential exists which is a significant energy resource as water but less than 1 percent of the potential power has been harnessed. According to the World Bank Report, 2014, the largest 23 dams in Nepal would have an installed capacity of about 25,000 MW, producing an estimated 65-70 Terra Watt hours of power annually with 
net value estimation of about 5 billion USD annually. Compared with other countries, Nepal has a high energy consumption in relation to its Gross Domestic Product (GDP) but does not yet have a strategy for sustainable, effective and efficient energy use.(www,energyefficiency.gov.np; Assessed: October 15, 2017). Hence, from the above facts it could be well enunciated that the doors of opportunities for hydropower development in Nepal is so immense and mammoth that the harnessing of hydro resources could be the best options not only for the country to drastically upsurge and proliferate the economic status but also for the private investors to effortlessly earn a reasonable profit.

\section{B. Possibility of mega dams with huge storage capacity:}

Many studies reveal that Nepal has tremendous possible capacities of mega dams with huge storage capacity that can not only render the hydropower facilitation to the Nepalese but also aid in flood control and regulated flow to the downstream riparian. It has been perspicuously portrayed in the World Bank Report (Ganges Strategic Basin Assessment, 2014) by adopting a number of modelling (both the water simulation and economic optimization model) to represent the current baseline condition, scenarios and outputs with the combination of three mega dams in Nepal (Pancheswar Dam on the Mahakali/Sharda River, Chisapani Dam on the Karnali/Ghagara River and Koshi High Dam on the Koshi River) as well as for 20 smaller dams in Nepal. The basic conclusions from the modelling as adverted in the World Bank Report could be summed up as below:

The three mega dams (Pancheswar Dam, Chisapani Dam and Koshi High Dam) with installed capacity of about 19,000 MW has a potential to produce about 35-45 terawatt hours of electricity annually. The remaining 11 dams, corresponding to $4600 \mathrm{MW}$ of installed capacity, could generate at least 18 terawatt hours electricity annually. 20 smaller dams as manifested in the exclusive model (exclusive of 3 mega dams) could yield about another 26-30 terawatt hours per year. The current hydropower production in the entire Ganges Basin in Nepal is about 12 terawatt hours annually and the current installed hydropower capacity is about $800 \mathrm{MW}(\mathrm{Nepal}$ Electricity Authority, 2017) which is projected to accrue up to about 1800 MW by 2019-2020.

\begin{tabular}{|c|c|c|c|}
\hline Dam & River & Total height (m) & Gross Storage Capacity (BCM) \\
\hline \multicolumn{4}{|l|}{ Existing } \\
\hline Tehri & Bhogirathi & 261 & 3.5 \\
\hline Marsyangdi & Marsyangdi & 240 & 6 \\
\hline Lakhwar (Under construction) & Yamuna & 204 & 0.6 \\
\hline Utyasu (Under construction) & Alaknanda & 175 & 3.7 \\
\hline Kalagadh & Ramganga & 128 & 0.3 \\
\hline Kulekhani & Bagmati & 107 & 0.1 \\
\hline \multicolumn{4}{|l|}{ Proposed } \\
\hline Budhi Gandaki & Budhi Gandaki & 300 & 3.2 \\
\hline Upper Karnali & Kamali & 260 & 7 \\
\hline Bheri 4 & Bheri & 260 & 15.8 \\
\hline Kali Gandaki A & Kali Gandaki & 260 & 6.9 \\
\hline Pancheshwar & Sarda & 250 & 6.8 \\
\hline West Sefi (Seti 6) & West Seti & 240 & 3.1 \\
\hline Chisapani & Kamali & 240 & 28.2 \\
\hline Sapta Koshi High & Koshi & 220 & 13.5 \\
\hline Sefi 1 & West Seti & 195 & 1.5 \\
\hline Sun Khosi & Sunkoshi & 180 & 1.5 \\
\hline Kali Gandaki 2 & Kaligandaki & 160 & 5.1 \\
\hline Pumagiri & Sarda & 150 & 3.4 \\
\hline Tamur Mewa & Tamur & 150 & 1.9 \\
\hline Sefi & Seti & 145 & 4 \\
\hline Trisuli & Trisuli & 140 & 11.0 \\
\hline Andhi Khola & Kali Gandaki & 110 & 0.9 \\
\hline International Dams & River & \multicolumn{2}{|c|}{ Total height (m)Gross Storage Capacity (BCM) } \\
\hline Nurek' & Vokhsh, Tajikiston & $300^{\circ}$ & 10.5 \\
\hline Hoover ${ }^{2}$ & Colorodo, USA & 221 & 35.2 \\
\hline Three Gorges ${ }^{3}$ & Yangtze, China & 175 & 39.3 \\
\hline Aswan ${ }^{4}$ & Nile, Egypt & 111 & 169 \\
\hline
\end{tabular}

Table 2:- Existing and Proposed Dams in the Ganges Basin over 100m High, with Global Comparators (Source: World Bank Report, Ganges Strategic Basin Management, 2014) 
ISSN No:-2456-2165

Because of geopolitics and essentiality of Trans boundary negotiation it might take several years to design, build and operate hydropower in Nepal but it is perspicuous that this region has a rising energy demand and do has a potential to satisfy the energy needs of India as well. India has a shortfall of about 1,00,000 MW of power today and thus it is essential for India as well to have a fruitful bilateral dialogue with Nepal for amelioration of hydropower sector in both the countries.

Installed capacity is the theoretical capacity of all turbines of a power plant if they were run at full design capacity all the year round. In a monsoonal climate like the Ganges if the very large scale storage is absent, deprival of adequate river flows in many months each year would be faced resulting inadequacy for running all the turbines at their full capacity. Installed capacity is important for high value peak load potential but actual power generation (in mega-watt hours or terawatt hours) is critical and fundamental for accessing the economic benefits of the country.

For. e.g. As depicted by modelling analysis (World Bank Report, 2014), the Koshi High Dam has anticipated installed capacity of about 3500 megawatts but can produce more energy than the Chisapani High Dam which has an installed capacity of more than 10,000 MW. Similarly, 20 smaller dams have a potential of just over a quarter of the installed capacity of the three mega dams but can generate more than half the power of the full suite of dams.

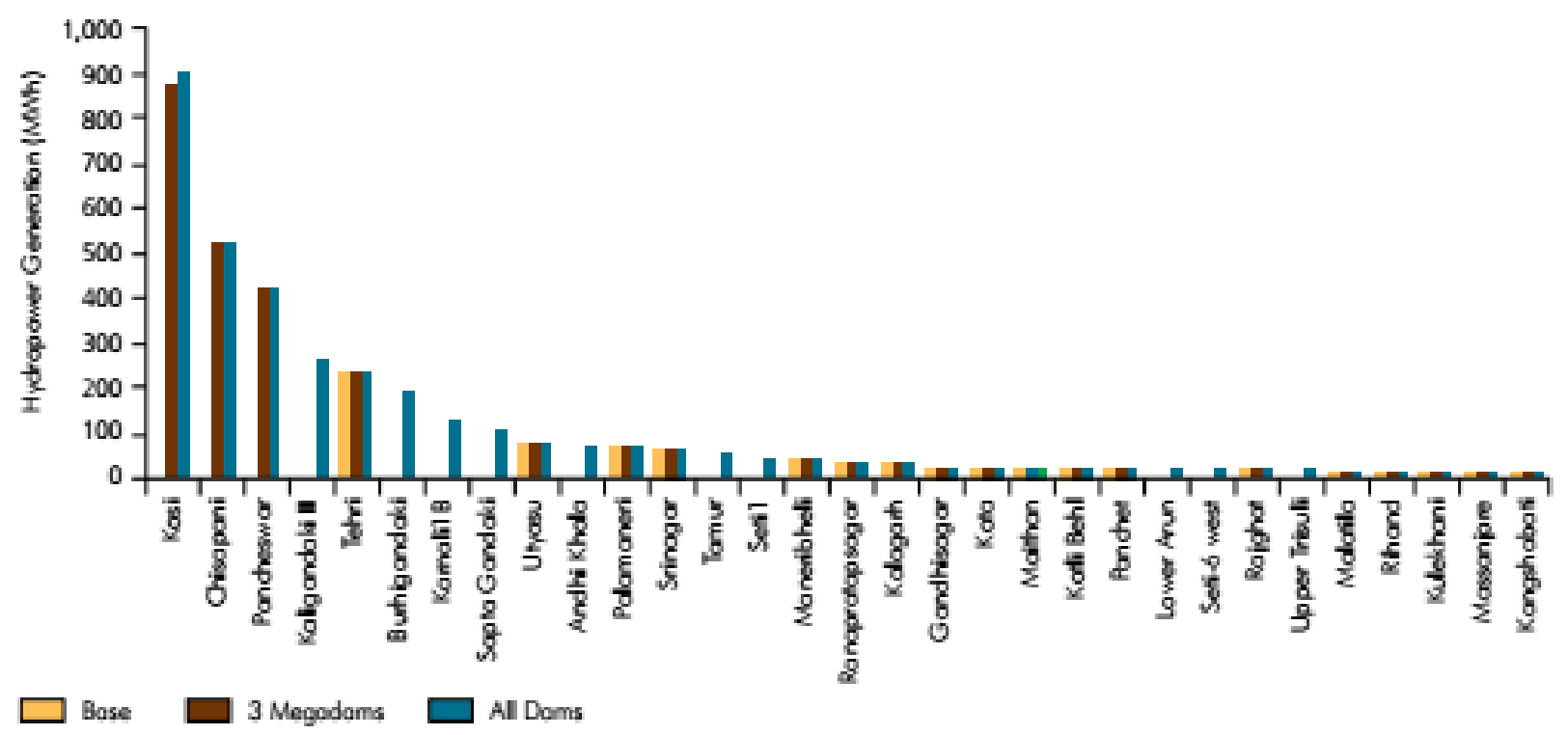

Fig 3:- Hydropower Potential in the Ganges Basin

(Source: World Bank Report, Ganges Strategic Basin Management, 2014)

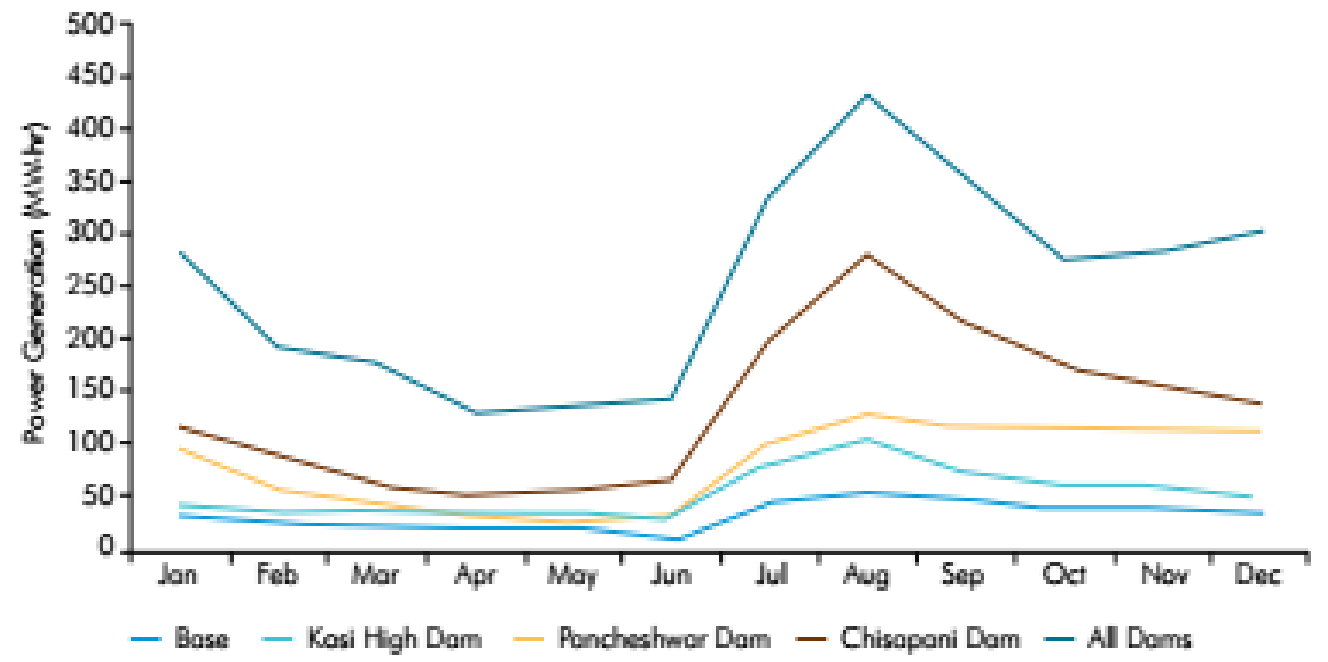

Fig 4:- Monthly Generated Hydropower based on Model Results

(Source: World Bank Report, Ganges Strategic Basin Management, 2014) 
Above Figure 3 vividly portrays that during limited storage available and short monsoon season, the seasonal variations in hydropower production from storage dams in the Ganges Basin would be probably considered. This relevancy is seen even more significant for run off the river projects that have no storage dams, but yet are regulated by a considerable storage upstream providing a more consistent flow throughout the year. Fig-4 illustrates in a pellucid manner that the actual power generated could be lower, marked by seasonal fluctuations through the consistent deliberation of power with full installed capacity (megawatts) of the proposed dams throughout the year.

Besides intra-annual (seasonal) variability, it seems important to recognize the highly variable flows from year to year. Since the hydropower production has no over year storage, it therefore displays strong inter-annual fluctuations. This results from the modelling (World Bank Report, 2014) limpidly display that there is indeed a significant potential for hydropower generation in Nepal which could readily satisfy her own domestic and industrial demand and even export the surplus energy to India.

\section{Possibility of Multipurpose Diversion Schemes} (including tying up with other water resources like riparian rights, upstream and downstream benefits)

Many large scale storage projects like Pancheswar Dam, Chisapani Dam and Koshi High Dam, having anticipated installed capacity of about $19000 \mathrm{MW}$ producing about 35-45 terawatt hours of electricity annually (World Bank Report, 2014)could be the large scale projects with multipurpose schemes for Nepal. Similarly, Budhigandaki Hydropower project, Dudhkoshi Storage Hydroelectric Project, Upper Arun Hydroelectric Project, Tamakoshi Hydroelectric Project, Andikhola Storage Hydroelectric Project, Uttar Ganga Storage Hydroelectric Project, Tamor Storage Hydroelectric Project, Chainpur Seti Hydroelectric Project etc. are some of the large scale feasible hydropower projects in Nepal. Such large scale projects could be used for multipurpose schemes in addition to hydropower gearing up to flood control, river navigation, irrigation, drinking water, recreational purpose etc. Such projects could even create benefits to the downstream countries, such as the Columbia River Project in the United States and Canada, the Mekong River Basin (Cooperation/ Consultation between Cambodia, Laos, Thailand and Vietnam), agreement between South Africa and Lesotho Highland Water Project etc. Such international Basin development initiatives reflect that benefits and costs of project should be shared between riparian states.

\section{Export of Surplus Energy}

Theoretically, generated electricity in Nepal could be transmitted to Bangladesh, Bhutan, India, Pakistan and the Tibet region of China. Except Tibet (China), however electricity exports of other countries requires political, technical and diplomatic back up from India since transmission lines to other countries would have to cross Indian territory. India, by developing a number of hydropower projects in Bhutan, is importing most of the energy generated there and thus may not be overly keen to buy electricity from Nepal at present. If Indian market is to be attracted by Nepal, a good will should be generated and Nepal must be willing to share the downstream benefits of proposed facilities. Nepal feels particularly singled out in regard to her treaties with India because water resources project developed with Indian assistance failed to bring perceptible and discernible economic amelioration in Nepal.

Hence Nepal and India both should build a strong diplomatic foundation with each other in regard to power export and India must freely accept the internationally recognizable right that a landlocked and upstream country could exercise.

\section{E. Cross Border Grid and Integration of South Asian Pool}

The Bay of Bengal Initiative for Multi-Sectoral Technical and Economic Cooperation (BIMSTEC), which has Bangladesh, Bhutan, India and Nepal as members, in order to coordinate, facilitate and strengthen cooperation in the energy sector in the region, established an Energy Centre in Delhi in 2011. The main objective of it was to help develop the cross border energy trade and a regional market for hydropower from Nepal and Bhutan. India has agreed to export $250 \mathrm{MW}$ of electricity to Bangladesh through Bangladesh-India grid connection and cross border $400 \mathrm{kV}$ electricity transmission lines between Nepal and India are under construction.

Cross border grid connections are increasing all over the world which already exists in North America, Europe and Southern Africa. Among them are the Nord Pool (Denmark, Finland, Norway, Sweden) and the South African Power Pool (12 Countries). The establishment of power grid networks and introducing power trading can help promote the effective utilization of untapped water resources and increase the water security in the region, which are the fundamental aspects of economic prosperity and improved living standards of the people. The physical and institutional demand for energy cooperation is steadily growing, which will provide a solid basis for cooperation in Trans boundary water (Ganga, Brahmaputra, Meghna Basins, 2014).

The cross border grid between the South Asian Countries (particularly among Nepal, India and Bangladesh) could be expanded and utilized to transfer power (energy) as grid integration could help India for using transmission lines in Bangladesh to transfer electricity to northeastern states and using the same grid, electricity produced in Nepal could be transferred to Bangladesh. Pooling surplus power through an integrated grid could create a reliable, smoother and acceptable supply of electricity and in addition would make the maintenance of generating stations much easier in grid connected countries. Load shifting, due to different time zones in South Asian countries, would even assist in avoiding the need for new facilities and would aid in optimizing the power operation system. (Shaligram Pokharel, 2001) 


\section{F. Upstream benefits and advantages:-}

Being in the upstream, Nepal (the Himalayas) possess a plentiful of technically feasible benefits and advantages which could be outlined as below:

\section{High heads :}

Discharge and head are the most fundamental parameters required that underlines and guides the power generation from any hydro project. Nepal is blessed by nature with topographical steep gradients, meandering nature of rivers in hills, easily available high heads (from head works to tailrace) and naturally present huge rocky dams (natural alternative to high dams) which makes it a naturally notional place for the hydropower generation. Similarly, blessed naturally with perennial rivers also makes the presence of minimum average flow in the river all the year round. Comparing among the two, high head rather than discharge is a real god-gifted boon to the Himalayan country Nepal for harnessing her hydro resources to the maximum potential for the utmost generation of electricity.

\section{Less sediment yield:-}

One of the fundamental upstream benefits is the less rate of sediment yield. High rate of sedimentation is a great obstacle and hindrance for storage projects in hydropower as it inevitably decreases the life of reservoir (by decreasing the dead storage capacity) and quartz (silt) gradually deteriorates the turbine components. Sediment production in Nepalese watersheds has generally been acknowledged to be highest in the world (Carson, B., 1985; ICIMOD Occasion paper No. 1 , 'Erosion and Sedimentation process in the Nepalese Himalaya'). So, construction of structures in the upstream would yield lower rate of sedimentation which would substantially favor the Nepalese context.

\section{Cascade projects:-}

If the hydropower projects are developed upstream, then the cascade projects could be developed in order which would not only reduce the cost of construction (tailrace of initial would be the headwork of next) but also the regulated flow could be discharged downstream. Nepal is most favorable for cascade projects being in upstream and one of the exemplary design of it is Kulekhani I (60 MW),
Kulekhani II (32MW) and Kulekhani III (14 MW) respectively.

\section{G. Replacement of fossil fuels :-}

It is a matter of burning discussion in the today's world that whether alternative energy sources as biofuels, hydrogen, solar, hydropower, geothermal or nuclear energy can meet the energy demands better than finite fossil fuels such as oil and coal. It could be portrayed that the best replacement for fossil fuels for electricity production is hydropower as it is among the preeminent renewable source to meet the growing demands. Hydropower could be one of the best alternatives for the power sector to replace fossil fuels, save energy and reduce emission.

After coal, hydropower is the second largest source of energy of China for which it is expected that the total installed hydropower capacity of China is to be about 350 Giga Watts (GW) by 2020. Similarly, China has a total of 80,000 dams built which is more than the combined dams of US, Brazil and Canada. If the remaining hydro of China is harnessed, about one-fifth of her peak energy demand could be met and about 1.3 billion tons of coal could be displaced. (www. nepalenergyforum.com, Assessed: October 13, 2017)

Despite huge hydropower potential, still around $85 \%$ of the total final energy consumption in Nepal is met by traditional bio mass energy and around $28 \%$ of households (HHs) in Nepal don't have access to electricity. (Renewable Energy Subsidy policy, 2073 B.S)

Biomass, comprising of wood, agricultural residues and dung, is by far the primary energy source in Nepal as $95 \%$ of the biomass is predominantly and traditionally used for cooking and heating purposes in households. Petroleum products, all imported from India, are the second largest energy consumption in Nepal and accounts for $8 \%$ energy consumption.

Coal , apart from minor reserves all imported from India, accounts for $2 \%$ of the total energy consumption and is almost exclusively consumed by the industrial sector, primarily for heating and boiling processes in brick, lime and cement production as well as in steel processing.

\begin{tabular}{|c|c|c|c|}
\hline S.No. & Fuel Types & Amount (GJ) & Percentage Share \\
\hline 1 & Fuel Wood & 352229.10 & 70.47 \\
\hline 2 & Agriculture Residue & 17408.43 & 3.48 \\
\hline 3 & Animal dung & 18401.96 & 3.68 \\
\hline 4 & Coal & 19819.09 & 3.97 \\
\hline 5 & Petroleum & 62618.27 & 12.53 \\
\hline 6 & Electricity & 16932.75 & 3.39 \\
\hline 7 & Renewable & 12430.26 & 2.49 \\
\hline
\end{tabular}

Table 3:- Distribution of Energy Consumption by Fuel Types in Fiscal Year 2014/15 (Source: WECS Report, 2017) 


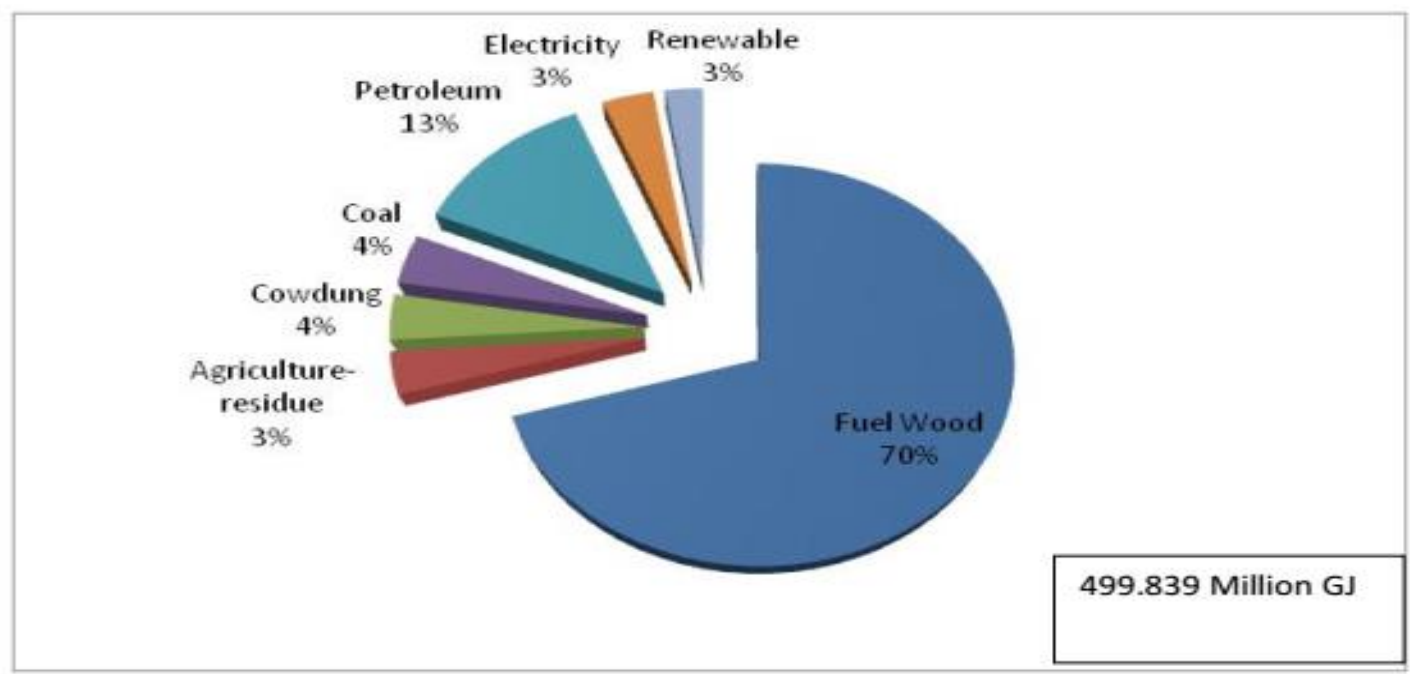

Fig 5:- Share of Energy Consumption by Fuel Types in 2014/15

(Source: WECS Report, 2017,'Electricity Demand Forecast Report")

Some of the advantages of hydropower over fossil fuels in context of Nepal can be outlined as:

- Hydropower is a clean source of energy (fuelled by water) compared to fossil fuels (coal or natural gas)

$>$ Hydroelectric power is an internal (domestic) source of energy, impelling each nation to produce from their own resources without being contingent on international fuel sources.

> Hydropower depends on water cycle, driven by the sun making it a renewable power source, making it more reliable and affordable source than fossil fuels.

$>$ Hydropower plants can initiate from zero to maximum output and since connection to the power grid can be done immediately, they provide essential backup during major electricity outages or disruptions.

$>$ Hence, hydropower could be the best option and the only alternative to meet the growing demands of energy consumption and could be the best alternative to replacing of fossil fuels.

\section{H. Huge Demand of Electrical Energy from Hydropower:}

The uprising demand of electrical energy over all other forms of energy is so high in Nepal that the load forecasting also seems quite challenging. Energy demand forecast is fundamental not only for the future energy planning of the country but also for the investors to invest in accordance with the growing demand of the market.

The energy demand forecast as carried out by Model for Energy Demand Analysis (MAED), which is a bottom up model reflected the following findings (WECS, 2017):

Main inputs and outputs of MAED were as follows:

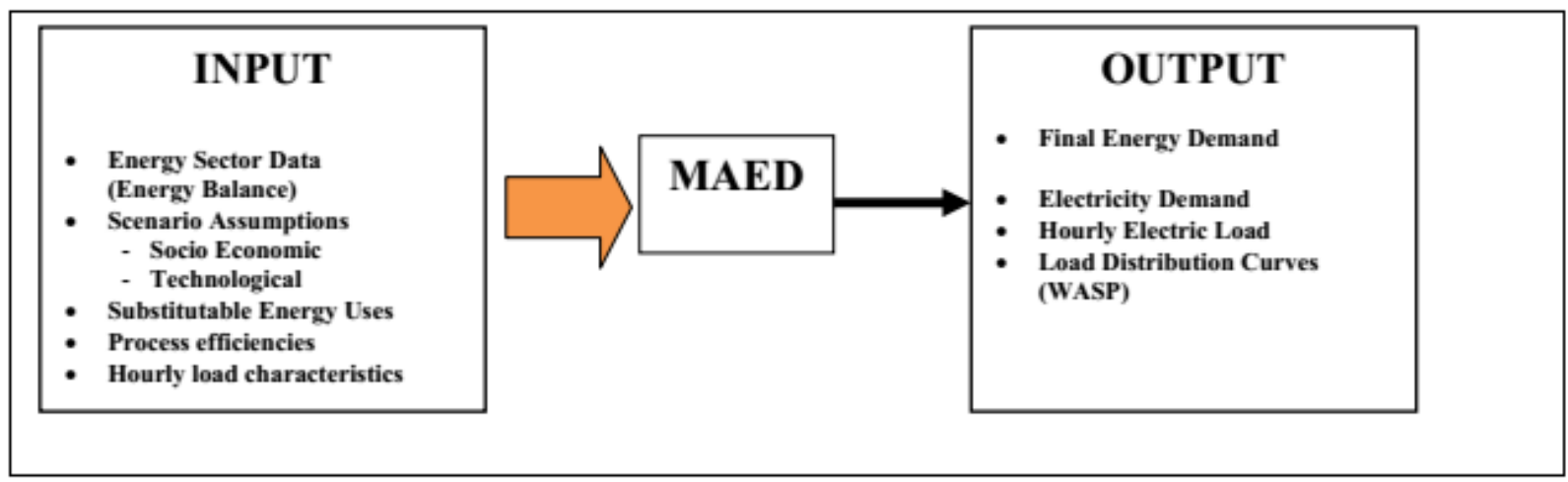

The study manifested that the electricity requirement depends on the population, economic conditions/activities (GDP), development path of the country, low carbon path (changes the demand pattern), plan/policy vision of the country. The study was conducted anticipating the policy interventions by the nation and the creation of enabling environment for using electricity in cooking and water heating in urban
Fig 6

areas, mechanization in agriculture, operation of electric trains etc.

$>$ The modeling done according to WECS report portrayed that the demand of electricity would rise by $30 \%$ in 2020 as compared to that in 2015. Even following the past trend of GDP growth at $4.5 \%$,there seems the necessity of about 3384 MW of installed capacity by 2020 and more over if the policy intervention is being done ,the 
requirement would double to 6621MW. By 2030, the installed capacity requirement seems to be about $15,000 \mathrm{mw}$ whereby the requirement seems to be more than 35,000 MW by 2040 thereby increasing demand of energy to $82,000 \mathrm{GW}$. If the policy intervention is being made to achieve $9.2 \%$ GDP growth rate, the necessity of installed capacity would reach up to $18,000 \mathrm{MW}$ in 2025 and more than $50,000 \mathrm{MW}$ by 2040 . In the study, it was the findings that the highest power demanding sector would be industry followed by household, service and transport sectors (WECS, 2017, Electricity Demand Forecast Report (2015-2040)).

\begin{tabular}{|c|c|c|c|c|c|c|c|c|c|c|}
\hline \multirow[t]{2}{*}{ Year } & \multicolumn{5}{|c|}{ Final Electricity Demand (GWh) } & \multicolumn{4}{|c|}{$\begin{array}{l}\text { Growth Rate of Final Electricity Demand } \\
\text { (\% p.a.) }\end{array}$} & \multirow[b]{2}{*}{$\begin{array}{c}\text { Policy } \\
\text { Intervention } \\
@ 9.2 \%\end{array}$} \\
\hline & BAU & $\begin{array}{l}\text { Reference } \\
\text { Scenario }\end{array}$ & $\begin{array}{c}\text { High } \\
\text { Scenario }\end{array}$ & $\begin{array}{c}\text { Policy } \\
\text { Intervention } \\
@ 7.2 \%\end{array}$ & $\begin{array}{c}\text { Policy } \\
\text { Intervention } \\
@ 9.2 \%\end{array}$ & BAU & $\begin{array}{l}\text { Reference } \\
\text { Scenario }\end{array}$ & $\begin{array}{c}\text { High } \\
\text { Scenario }\end{array}$ & $\begin{array}{c}\text { Policy } \\
\text { Intervention } \\
\text { @ 7.2\% }\end{array}$ & \\
\hline 2015 & 3866.3639 & 3866.363904 & 3866.36 & 3866.36 & 3866.36 & & & & & \\
\hline 2020 & 7600.75872 & 8110.66 & 8522.97 & 14870.92 & 15304.29 & 14.5 & 15.10 & 17.13 & 30.92 & 31.67 \\
\hline 2025 & 12998.2503 & 14863.67 & 16545.84 & 22431.68 & 24265.05 & 11.3 & 12.19 & 14.19 & 8.57 & 9.66 \\
\hline 2030 & 20073.8344 & 24956.79 & 29864.09 & 35334.66 & 41264.82 & 9.1 & 10.25 & 12.54 & 9.51 & 11.20 \\
\hline 2035 & 29744.6919 & 40709.77 & 52983.16 & 51771.84 & 65657.50 & 8.2 & 9.64 & 12.15 & 7.94 & 9.73 \\
\hline 2040 & 43016.6893 & 66096.60 & 94851.06 & 81958.97 & 115294.44 & 7.7 & 9.50 & 12.35 & 9.62 & 11.92 \\
\hline
\end{tabular}

Table- 4:- Total Final Electricity Demand and Average Growth Rates (Source: WECS, 2017).

(Note: BAU- Business as Usual @ 4.5\% GDP Growth Rate)

Hence, it seems quite obvious that there are abundant doors of opportunities for hydropower development in Nepal for investors to secure their market but above all these a strong political will comprehending infrastructure development and financial investment is a must.

\section{Enhancement of economic prosperity thereby attainment of Sustainable Development Goals (SDGS):-}

Sustainable development Goals, scaled-up from the Millennium Development Goals in 2015, has been geared up in the Nepalese context through 'SDG Voluntary Review: Eradicating Poverty and Promoting Prosperity in Nepal'. Mainstreaming of SDGs have been initiated by Nepal Government in national planning and budgeting system by systematically integrating it in the periodic plan. In 2016, the Nepal government in collaboration with the private sector held a power summit to attract investors in electricity generation. The assurance from government regarding investor pleasant conditions and establishment of a coordination committee to simplify the administrative procedures seemed to love the investors. The government is also exercising to adjust electricity tariffs in line with the power purchase agreement rate, providing an incentive of Rs.5 million per megawatt for private hydropower developers and tax exemptions. Investors from India, China, Bangladesh, Singapore, Germany, UK and Norway seem interested in investing in Nepal's energy sector (National Planning Commission, 2017).

The economic prosperity could be easily attained through hydropower development and some of the benefit sharing mechanisms in hydropower for economic enhancement of people can be distilled as (ICIMOD, 2016):
Provision of Royalty

Financial share of local community: Equity Investment

$>$ Sustenance for local livings: employment and training.

$>$ Investment in community development and local infrastructure (including rural electrification and irrigation) water related benefits).

$>$ Ecological enrichment actions.

Moreover, acknowledgement of benefit sharing not as a panacea but as a solid foundation towards economic prosperity would aid as a safeguard to boost up for prosperous economy in Nepal. In addition to this, it is limpidly enunciated in various policies (e.g. Royalty) and practices (e.g. equity shares, community development) of Nepal that benefit sharing is beyond mere compensation and mitigation. Hence, through cooperation between the various concerned stakeholders, the economic prosperity of the Nepalese leading to country's overall economy could be better exponentially stepped-up.

\section{CONCLUSION}

The gigantic hydro resources of Nepal (the Himalaya) have been befittingly coined by many as nature's magnanimous boon to her. Actually, the perennial nature that Nepalese rivers owe, the topographical steep gradient, easily available high heads, readily present (by nature) huge rocky dams (natural alternative to huge concrete dams), possibility of project implementation in cascades (being at upstream) etc. provides a solid foundation for harnessing enormous hydropower potential through the development of mega hydroelectric projects. Nepal's economic prosperity is highly dependent and reliable on the priggish, puritanical and judicious development of her hydro resources but 
however there still remains a lot to be performed to create an attractive, decorative and strengthened enabling environment for luring bigger investment to hydro sector.

The generated electricity form hydropower would aid the least developed countries like Nepal to prosper economically by intense industrialization, employment generation and so on. On one hand, the hydropower development can replace the petroleum products thereby reducing trade deficit with India and on the other hand, the firewood consumption could be inevitably reduced enunciating the reduction in deforestation rate and saving the environment.

The demand of electrical energy over all other forms of energy and that of the total installed power generation capacity in Nepal is quite a hot cake and a burning issue. It is the primary responsibility of government to concentrate all its efforts in a unified manner to supply the power as per demand of consumers to innervate the entire economic sector. Moreover, hydropower is the sector in Nepal where apart from public sector, a lot of private sector developers along with national and international investors are keenly interested to make huge investments. Hydropower is the cynosure of investment in Nepal, fundamentally because of its huge potential and astounding domination in the power sector, which inherently has prolonged parturiency and almost wholesome generation cost is in the form of upfront capital investment.

Hence, crawling through pros and cons, hurdles and opportunities, ups and downs of hydropower development in Nepal, one can fundamentally foster out the higher weightage of possible opportunities and implement it accordingly. Analyzing all these issues, challenges and opportunities underlined, it could be perspicuously concluded that collaborative and united efforts of all differently positioned project stakeholders- from the project developer to government actors, and policy makers, to institutional investors and donor agencies, to consumers and electricity users and project affected population is vital, fundamental and indispensable as well.

\section{REFERENCES}

[1]. Adhikari, D., 2006, Hydropower Development in Nepal

[2]. Agrawal, S., Reyoholds et.al. 2003, Development and Climate change in Nepal: Focus on Water Resources and Hydropower.

[3]. Baral, S., 2014, Fundamentals of Hydropower Engineering

[4]. ICIMOD, 2016, Benefit sharing and sustainable Hydropower: Lessons from Nepal

[5]. Institute of Foreign Affairs, IFA, 2010, STATEMENTS AND DECLARATIONS OF SAARC Summits of the Heads of State or Government, mKathmandu, Nepal

[6]. Keshar Man Sthapit, 1996, Sedimentation Monitoring of Kulekhani Reservoir, International Conference on Reservoir Sedimentation Fort Collins Colorado, USA.
[7]. National Planning Commission, 2017, 14 ${ }^{\text {th }}$ National Plan

[8]. Nepal Electricity Authority, Annual Report, 2017

[9]. Pokharel, S., 2001, Hydropower for Energy in Nepal, Mountain Research and Development, Vol. 21, Issue 1, Page 4-9, hhtps://doi.org/10.1659/02764741(2001)021 [0004:HFEIN] 2.0.Co;2)

[10]. Rechsteiner,R., 2001, In: Mountain Agenda, Mountains of the World: Mountains, energy and transport. Berne: Centre for Development and Environment.

[11]. Shrestha, R.S., 2007, Investment in Hydropower Sector: Opportunities and Risks, Hydro Nepal Vol. 1 Issue-1

[12]. South Asia Sub regional Economic Cooperation Power System Expansion Project, 2013 [(RPP NEP44219), 2013)]

[13]. Uprety, B.N., 2000, The Physiography and Geology of Nepal and their Behaving on the Landslide Problem.

[14]. WECS, Water and Energy Commission Secretariat, 2017, Electricity Demand Forecast Report (20152040)

[15]. World Bank, 2014. Ganges Strategic Basin Assessment: A Discussion of Regional Opportunities and Risks.

[16]. Www. nepalenergyforum.com, Assessed: October 13, 2017

[17]. www.energyefficiency.gov.np; Assessed: October 15, 2017

[18]. www.wikipedia.org, Assessed: 16 October, 2017. 